\title{
Tooth mobility parameters in chronic periodontitis patients prior to periodontal therapy: A cross-sectional study
}

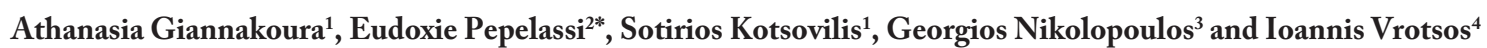 \\ ${ }^{1}$ Practicing periodontist in Athens, Greece \\ ${ }^{2}$ Associate Professor, Department of Periodontology, School of Dentistry, National and Kapodistrian University of Athens, Athens, Greece \\ ${ }^{3}$ Assistant Professor of Epidemiology and Public Health, Medical School, University of Cyprus, Nicosia, Cyprus. \\ ${ }^{4}$ Professor and Chair, Department of Periodontology, School of Dentistry, National and Kapodistrian University of Athens, Athens, Greece
}

\begin{abstract}
Background: Animal experiments have proved that increased tooth mobility may primarily result from periodontitis, alone or combined with trauma from occlusion. However, additional clinical studies on tooth mobility parameters would be desirable. Therefore, the aim of this cross-sectional study was to examine the potential association of various parameters (patient- and tooth-related clinical, radiographic and anatomical parameters) with the presence and grade of mobility of periodontally involved teeth in chronic periodontitis patients, prior to the initiation of periodontal therapy.
\end{abstract}

Methods: Forty chronic periodontitis patients with 683 periodontally involved teeth were studied. Clinical measurements of full-mouth plaque score (FMPS), gingival index simplified (GI-S), full-mouth bleeding on probing score (FMBS), clinical attachment loss (CAL), probing pocket depth (PD) and tooth mobility grade, and radiographic measurements of linear radiographic alveolar bone support (RBS) and loss (RBL) were performed. The type of radiographic alveolar bone loss (TRBL; horizontal or angular) and the presence of any periapical radiolucency (PR) with dimensions $\geq 1 \mathrm{~mm} \times 1 \mathrm{~mm}$ were also recorded. Statistical analyses evaluated the association of dichotomous or continuous variables with tooth mobility presence and grade.

Results: Maximum CAL and PD per tooth, mean (mesial and distal) RBL per tooth, smoking, presence of a single-rooted tooth or PR were statistically significantly positively associated with tooth mobility grade; mean (mesial and distal) RBS per tooth was statistically significantly negatively associated, whereas no association was demonstrated for patient age, gender, FMPS, GI-S, FMBS and TRBL.

Conclusions: Within its limits, this study found that the main parameters affecting tooth mobility grade are tooth-related, including anatomical (number of roots), clinical (maximum clinical attachment loss and probing pocket depth per tooth) and radiographic parameters (mean radiographic alveolar bone loss and support per tooth, the presence of periapical radiolucency). Tooth mobility was also affected by smoking.

Key result: The main parameters of tooth mobility grade are maximum clinical attachment loss per tooth, maximum probing pocket depth per tooth, linear radiographic bone loss or support per tooth, smoking and presence of a single-rooted tooth or periapical radiolucency.

\section{Introduction}

Physiological/normal tooth mobility may be defined as the slight displacement of the clinical crown of a tooth, that is allowed by the resilience of an intact and healthy periodontium, under the application of a moderate force [1,2]. Increased tooth mobility/ hypermobility (subsequently termed "tooth mobility" in the present study) could be defined as the clinically perceptible tooth movement or displacement in bucco-lingual (-palatal), mesio-distal and/or vertical (apico-coronal) direction, when the tooth is exposed to a small force (e.g. $0.25 \mathrm{~N})$ [3].

Over the past decades, an extensive bulk of studies, the majority of which were animal experiments, conclusively documented that the main causes of tooth mobility are the widening of periodontal ligament and/or the destruction of supporting periodontal tissues, most usually resulting from the presence of active or treated periodontitis (presence of non-inflamed periodontium with reduced periodontal support), either alone [4-6] or combined with trauma from occlusion [6-16].
As reviewed in the literature $[2,17]$ the degree of tooth mobility may be influenced by a wide variety of factors, such as: the root surface area with connective tissue attachment and therefore tooth type and morphology (e.g. crown-to-root ratio, number, shape and length of roots etc.) and the structural, biophysical (e.g. viscoelasticity and resilience) and metabolical properties of the periodontal ligament and the supporting alveolar bone. All the above-mentioned properties may be affected by functional (e.g. intensity and direction of occlusal forces),

${ }^{\star}$ Correspondence to: Eudoxie Pepelassi, Associate Professor, Department of Periodontology, School of Dentistry, National and Kapodistrian University of Athens, 2 Thivon St., GR 11527, Athens, Greece, Tel.: +30 210 746-1223, 7461203,E-mail: epepela@dent.uoa.gr

Key words: association, chronic periodontitis, cross-sectional study, periodontal status/condition, tooth mobility presence, grade and parameters

Received: January 10, 2019; Accepted: January 21, 2019; Published: January 23, 2019 
local (e.g. severity of periodontal inflammation) or systemic conditions (e.g. diabetes); such conditions could be either physiological (e.g. pregnancy) or pathological (e.g. periodontal or periapical abscess) [17].

Taking into account that tooth mobility may be affected by a plethora of factors, it is clinically important to examine the association of mobility with various parameters. A certain amount of information on various associated parameters has already been accumulated by research in humans during the past few decades [4,18-22], but it is clear that additional evidence originating from clinical research would further be desirable.

Therefore, the aim of the present cross-sectional study was to examine the potential association of various parameters with the presence and grade of mobility of periodontally involved teeth in chronic periodontitis patients, prior to the initiation of periodontal therapy. These parameters were subcategorized as follows:

- patient-related parameters: age; gender; presence or absence of smoking $\geq 10$ cigarettes / day,

- anatomical tooth-related parameters: tooth type according to the number of roots, i.e., presence of a single- or a multi-rooted tooth,

- clinical tooth-related parameters: full-mouth plaque score (FMPS) [23]; gingival index simplified (GI-S) [24]; full-mouth bleeding on probing score (FMBS) [25]; maximum clinical attachment loss $\left(\mathrm{CAL}_{\max }\right)$ per tooth; maximum probing pocket depth $\left(\mathrm{PD}_{\max }\right)$ per tooth and

- radiographic tooth-related parameters: mean (mesial and distal) linear radiographic alveolar bone loss (mean RBL) per tooth; mean (mesial and distal) linear radiographic alveolar bone support (mean RBS) per tooth; type of radiographic alveolar bone loss (TRBL), horizontal or angular; presence or absence of a periapical radiolucency with dimensions $\geq 1 \mathrm{~mm} \times 1 \mathrm{~mm}$ [26], as assessed on conventional periapical radiographs)

\section{Materials and methods}

\section{Patient and tooth population}

The study protocol was approved by the Ethics and Research Committee of the School of Dentistry, University of Athens, Athens, Greece and was conducted in accordance with the provisions of the World Medical Association's Helsinki Declaration of 1975, as revised in 2000. Forty Caucasian volunteers (14 males and 26 females; age range $31-66$ years; mean age $48.89 \pm 8.74$ years) were selected from the patient pool of the Department of Periodontology, School of Dentistry, University of Athens, Athens, Greece, based on the following inclusion/ exclusion criteria.

\section{Inclusion criteria}

- Systemically healthy Caucasians, aged $\geq 18$ years

- Diagnosis of generalized chronic periodontitis of any severity, according to the definition settled in the 1999 International Workshop for a Classification of Periodontal Diseases and Conditions [27]

- Presence of at least 15 periodontally involved teeth (single- and/or multi-rooted), without fixed or removable prosthetic restoration, occlusal interferences and/or trauma from occlusion, caries, fracture, gingival overgrowth, drug-induced gingival/periodontal conditions, periodontal abscess, endodontic pathology (including root resorption) or a combined periodontal-endodontic lesion.

\section{Exclusion criteria}

- History of previous periodontal therapy within 6 months before the screening examination

- Contraindications for radiographic examination (e.g. pregnant females) or general contraindications for clinical research (e.g. psychiatric problems.)

\section{Clinical examination}

The clinical examination of teeth and their periodontium was performed in all patients prior to the initiation of periodontal therapy and comprised measurements of the following clinical periodontal parameters: FMPS [23], GI-S [24], FMBS [25], clinical attachment loss (CAL), probing pocket depth (PD), gingival recession depth (REC) and the grade of tooth mobility. CAL was measured as the distance between the cemento-enamel junction (CEJ) and the clinically probeable base of each periodontal pocket, whereas PD was measured as the distance between the free gingival margin and the clinically probeable base of each periodontal pocket. REC was measured as the distance between the CEJ and the free gingival margin. If the CEJ was not distinguishable/usable as a reference point (e.g. due to fillings, erosion etc.), another alternative stable landmark served as the reference point for measurement. CAL, $\mathrm{PD}$ and REC were rounded off to the nearest millimeter.

Clinical measurements of FMPS, GI-S, FMBS, CAL, PD and REC were performed by the same masked and calibrated examiner (A.G.) in all patients on six aspects/sites per tooth: mesio-facial (-buccal), midfacial (-buccal), disto-facial (-buccal), mesio-lingual (-palatal), midlingual (-palatal) and disto-lingual (-palatal), using the same type of periodontal probe (PCP UNC-15, Hu-Friedy, Chicago, IL) with a mild probing force, corresponding to approximately $25 \mathrm{~N}$.

The examiner (A.G.) who performed the clinical measurements of FMPS, GI-S, FMBS, CAL, PD and REC was masked with respect to clinical measurements of tooth mobility, in order not to affect the results of the subsequent statistical analysis on the correlation of tooth mobility with clinical parameters. Clinical measurements of tooth mobility were performed by another examiner (E.P.), who was masked throughout the entire study period with respect to all other clinical and radiographic measurements. Calibration for the evaluation of intra-examiner reproducibility of periodontal probing had already been performed prior to the screening examination, using methods previously described $[28,29]$. In particular, five patients, each having at least 10 teeth (single- and multi-rooted) with $\mathrm{PD} \geq 6 \mathrm{~mm}$ on at least one aspect, were used to calibrate the examiner (A.G.). The examiner carried out a measurement of CAL and PD in duplicate and $48 \mathrm{~h}$ apart. The examiner was considered to be reproducible at an acceptable level, because at least $90 \%$ of the recordings at baseline and after $48 \mathrm{~h}$ were reproduced within a difference of $1 \mathrm{~mm}[28,29]$.

The mobility of each tooth was determined by holding the tooth between the handles of two metallic dental instruments and attempting to move it in all three directions, i.e. mesio-distally, bucco- (facio-) lingually (-palatally) and apico-coronally (vertically). The grade of tooth mobility was assessed three consecutive times and the most frequent measurement was finally selected and recorded.

Two grading systems were used to record the grade of tooth mobility: 
» A four-grade system (0, I, II, III), in accordance with the original classification of tooth mobility proposed by Nyman, et al. [30]

» A seven-grade system $(0,+$, I, I+, II, II+, III), which was a modification of the original classification of tooth mobility [30], produced by subdividing grade I to grades + and I, grade II to grades I+ and II and grade III to grades II+ and III, thus finally increasing the number of grades from four to seven, as defined below:

- Grade 0: No detectable displacement of the clinical crown

- Grade +: Movement of the clinical crown $\leq 0.5 \mathrm{~mm}$ bucco(facio-) lingually (-palatally) and/or mesio-distally

- Grade I: Movement of the clinical crown $>0.5 \mathrm{~mm}$, but $\leq 1 \mathrm{~mm}$ bucco- (facio-) lingually (-palatally) and/or mesio-distally

- Grade I+: Movement of the clinical crown $>1 \mathrm{~mm}$, but $\leq 1.5 \mathrm{~mm}$ bucco- (facio-) lingually (-palatally) and/or mesio-distally

- Grade II: Movement of the clinical crown $>1.5 \mathrm{~mm}$, but $\leq 2 \mathrm{~mm}$ bucco- (facio-) lingually (-palatally) and/or mesio-distally

- Grade II+: Movement of the clinical crown $>2 \mathrm{~mm}$, but $\leq 2.5 \mathrm{~mm}$ bucco- (facio-) lingually (-palatally) and/or mesio-distally

- Grade III: Movement of the clinical crown $>2.5 \mathrm{~mm}$ bucco(facio-) lingually (-palatally) and/or mesio-distally and/or any displacement (any millimeters) of the clinical crown apicocoronally (vertically).

\section{Radiographic examination}

For each patient, radiographic examination was performed prior to the initiation of periodontal therapy by means of an orthopantomograph and full-mouth periapical radiographs (14 periapical radiographs, in complete dentition), taken with the parallel cone technique, using the same x-ray generating dental radiographic unit (Oralix 65S, Gendex Dental System, Milan, Italy) operating at standardized conditions (65 $k V p$ and $7.5 \mathrm{~mA}$ settings and 0.32-0.45 s exposure time), as well as by using the same F-speed dental x-ray film (Kodak InSight Dental Film, Kodak Dental Systems, Carestream Health, Inc., Rochester, NY), processed automatically following exposure. All radiographs were taken by the same masked and calibrated operator (A.G.), who also performed the subsequent radiographic measurements.

For radiographic measurements, the radiographic images of the $\mathrm{CEJ}$ and the tooth apex served as stable reference points, whereas the alveolar crest level was the non-stable landmark [31]. RBL was measured by using the same conventional ruler (Fixot-Everett radiopaque grid, Oregon Health Sciences University, Portland, Oregon, USA), both mesially and distally to each tooth, as the distance (in millimeters) from the CEJ to the alveolar crest level (mesially and distally, respectively), as imaged on the periapical radiographs. RBS was measured by using the same conventional ruler, both mesially and distally to each tooth, as the distance (in millimeters) from the alveolar crest level (mesially and distally, respectively) to the tooth apex, as imaged on the periapical radiographs. Mean RBL per tooth or mean RBS per tooth was calculated as the mean value of the mesial and distal measurement of RBL or RBS, respectively, i.e. based on two measurements per tooth. If a periodontal endosseous defect was radiographically imaged, the distance from the alveolar crest level to the defect base level (depth of the endosseous component of the endosseous defect) and the mesiodistal defect width at the alveolar crest level were also measured [26]. By definition, periodontal endosseous defects were considered to radiographically present both depth of the endosseous component $\geq 1$ $\mathrm{mm}$ and mesio-distal defect width at the alveolar crest level $\geq 1 \mathrm{~mm}$ [26]. All radiographic measurements were rounded off to the nearest millimeter.

The examiner (A.G.) who performed all radiographic measurements was masked with respect to all clinical measurements (tooth mobility and FMPS, GI-S, FMBS, CAL, PD and REC), in order not to affect the results of the subsequent statistical analysis on the correlation of tooth mobility with clinical and radiographic parameters. It should be noted that the examiner (A.G.) who performed all radiographic measurements had also carried out all clinical measurements, except for tooth mobility. However, radiographic measurements were performed at a considerable period of time (two weeks) after the clinical measurements and without concomitant access to them. Calibration for the evaluation of intra-examiner reproducibility of radiographic measurements had already been performed prior to the screening examination, using methods analogous to those described above for clinical measurements $[28,29]$. In particular, five patients, each having at least 10 teeth (single- and multi-rooted) with $P D \geq 6 \mathrm{~mm}$ on at least one aspect, were used to calibrate the examiner (A.G.). The examiner carried out in duplicate and $48 \mathrm{~h}$ apart measurements of the mesial and distal RBS (in millimeters) of each tooth on the same radiograph. The examiner was considered to be reproducible at an acceptable level, because at least $90 \%$ of the recordings at baseline and after $48 \mathrm{~h}$ were reproduced within a difference of $1 \mathrm{~mm}$.

\section{Statistical analysis}

The association of dichotomous variables (gender; tooth type, single- or multi-rooted teeth; type of radiographic alveolar bone loss, horizontal or angular) with the presence or absence of tooth mobility was evaluated by using the $\chi^{2}$ test. The association of continuous variables (age, FMPS, GI-S, FMBS, $\mathrm{CAL}_{\text {max }}$ per tooth, $\mathrm{PD}_{\text {max }}$ per tooth, mean RBL per tooth and mean RBS per tooth) with the presence or absence of tooth mobility was assessed by the use of the WilcoxonMann-Whitney test for non-parametric data, because in this dataset all continuous variables did not follow the normal distribution, as revealed by the Shapiro-Wilk test $(p<0.01)$.

The association of dichotomous variables (gender; presence or absence of smoking $\geq 10$ cigarettes / day; tooth type, single- or multirooted teeth; type of radiographic alveolar bone loss, horizontal or angular; presence or absence of a periapical radiolucency with dimensions $\geq 1 \mathrm{~mm} \times 1 \mathrm{~mm}$ ) with the grade of tooth mobility was evaluated by using the $\chi^{2}$ test. The association of continuous variables (age, FMPS, GI-S, FMBS, $\mathrm{CAL}_{\text {max }}$ per tooth, $\mathrm{PD}_{\text {max }}$ per tooth, mean RBL per tooth and mean RBS per tooth) with the grade of tooth mobility was assessed by the use of the Kruskal-Wallis test for non-parametric data, because in this dataset all continuous variables did not follow the normal distribution, as revealed by the Shapiro-Wilk test $(p<0.01)$. Commercially available statistical software (Stata/SE 14.0 for Windows, Stata Corporation, College Station, TX) was used. The level of statistical significance was set at $5 \%(\mathrm{p}=0.05)$.

\section{Results}

All 40 patients safely completed the study, without any complications.

\section{Patient and tooth population (Table 1)}

The main characteristics of the patient and tooth population are summarized in Table 1. According to the definition of the severity of chronic periodontitis [27] (Armitage 1999), two patients exhibited mild 
Table 1. Patient and tooth population: main characteristics

\begin{tabular}{|c|c|}
\hline Population & Main characteristics \\
\hline \multicolumn{2}{|l|}{ Patient population $(N=40)$} \\
\hline $\begin{array}{l}\text { Age } \\
\text { Mean } \pm \text { SD; Range (years) }\end{array}$ & $48.89 \pm 8.74 ; 31-66$ \\
\hline Males $(N ; \%)$ & $14 ; 35.0 \%$ \\
\hline Females $(N ; \%)$ & $26 ; 65.0 \%$ \\
\hline Mild chronic periodontitis $(N ; \%)$ & $2 ; 5.0 \%$ \\
\hline Moderate chronic periodontitis $(N ; \%)$ & $9 ; 22.50 \%$ \\
\hline Severe chronic periodontitis $(N ; \%)$ & $29 ; 72.50 \%$ \\
\hline Smokers ( $\geq 10$ cigarettes / day) $(N ; \%)$ & $19 ; 47.50 \%$ \\
\hline Non-smokers (<10 cigarettes / day) $(N ; \%)$ & $21 ; 52.50 \%$ \\
\hline \multicolumn{2}{|l|}{ Tooth population $(N=683)$} \\
\hline Single-rooted teeth $(N ; \%)$ & $446 ; 65.30 \%$ \\
\hline Multi-rooted teeth $(N ; \%)$ & $237 ; 34.70 \%$ \\
\hline Maxillary incisors $(N ; \%)$ & $110 ; 16.11 \%$ \\
\hline Maxillary canines $(N ; \%)$ & $42 ; 6.15 \%$ \\
\hline Maxillary premolars $(N ; \%)$ & $88 ; 12.88 \%$ \\
\hline Maxillary molars $(N ; \%)$ & $100 ; 14.64 \%$ \\
\hline Mandibular incisors $(N ; \%)$ & $119 ; 17.42 \%$ \\
\hline Mandibular canines $(N ; \%)$ & $41 ; 6.0 \%$ \\
\hline Mandibular premolars $(N ; \%)$ & $89 ; 13.03 \%$ \\
\hline Mandibular molars $(\mathrm{N} ; \%)$ & $94 ; 13.76 \%$ \\
\hline
\end{tabular}

periodontitis, nine patients presented moderate periodontitis, whereas the remaining 29 patients had severe periodontitis. Nineteen patients were considered to be smokers (defined as consumers of $\geq 10$ cigarettes / day), whereas 21 patients were regarded as non-smokers $(<10$ cigarettes / day). In total, 683 periodontally involved teeth (446 single- and 237 multi-rooted teeth) were studied.

\section{Main clinical and radiographic outcomes (Tables 2 and 3)}

The grade of tooth mobility by tooth type according to the number of roots (single- or multi-rooted teeth) is presented in Table 2. The main clinical and radiographic parameters measured are summarized in Table 3. Horizontal radiographic alveolar bone loss appeared around 613 teeth $(89.75 \%)$, whereas angular radiographic alveolar bone loss was present in around 70 teeth (10.25\%). In total, 76 periodontal endosseous defects (44 mesial and 32 distal) were radiographically detected. The mean radiographic depth of the angular defects was 3.03 $\mathrm{mm} \pm 1.44 \mathrm{~mm}$, while their mean radiographic mesio-distal width was $2.36 \mathrm{~mm} \pm 1.24 \mathrm{~mm}$.

Presence or absence of tooth mobility associated with patientrelated, clinical and radiographic parameters (Table 4)

With respect to the association of dichotomous variables with the presence or absence of tooth mobility, the $\chi^{2}$ test revealed a marginally statistically significant $(p=0.043)$ relation to gender (males: $61.39 \%$ vs. females: $69.23 \%$ mobile teeth), whereas both the tooth type (single- or multi-rooted teeth) and the type of radiographic alveolar bone loss (horizontal or angular) were not statistically significantly associated $(p>0.05)$.

With respect to the association of continuous variables (age, FMPS, GI-S, FMBS, CAL max $_{\text {ax }}$ per tooth, $\mathrm{PD}_{\max }$ per tooth, mean RBL per tooth and mean RBS per tooth) with the presence or absence of tooth mobility, the Wilcoxon-Mann-Whitney test for non-parametric data revealed that $\mathrm{CAL}_{\text {max }}$ per tooth, $\mathrm{PD}_{\max }$ per tooth, mean $\mathrm{RBL}$ per tooth and mean RBS per tooth were statistically significantly related to the presence or absence of tooth mobility at varying levels of statistical significance $(p<0.01$ or $p<0.001$, Table 4$)$, whereas age, FMPS, GI-S and FMBS were not statistically significantly associated $(p>0.05)$. In particular, mobile teeth exhibited statistically significantly higher values of $\mathrm{CAL}_{\text {max }}$ per tooth, $\mathrm{PD}_{\text {max }}$ per tooth and mean $\mathrm{RBL}$ per tooth, and statistically significantly lower mean RBS per tooth, compared with non-mobile teeth (Table 4).

Grade of tooth mobility associated with patient-related, clinical and radiographic parameters (Table 4)

With respect to the association of dichotomous variables (gender; presence of smoking $\geq 10$ cigarettes / day; tooth type, single- or multirooted teeth; type of radiographic alveolar bone loss, horizontal or angular; presence or absence of a periapical radiolucency with dimensions $\geq 1 \mathrm{~mm} \times 1 \mathrm{~mm}$ ) with the grade of tooth mobility, the $\chi^{2}$ test revealed that gender and type of radiographic alveolar bone loss (horizontal or angular) were not statistically significantly associated with tooth mobility grade $(p>0.05)$. In contrast, statistically significantly higher tooth mobility was demonstrated for single-rooted teeth

Table 2. Tooth mobility grade by tooth type

\begin{tabular}{|c|c|c|c|}
\hline $\begin{array}{l}\text { Tooth mobility } \\
\text { grade }\end{array}$ & $\begin{array}{c}\text { Single-rooted teeth } \\
(N \& \%)\end{array}$ & $\begin{array}{c}\text { Multi-rooted teeth } \\
(N \& \%)\end{array}$ & $\begin{array}{c}\text { Total } \\
(N \& \%)\end{array}$ \\
\hline \multicolumn{4}{|l|}{$\begin{array}{c}\text { Original } \\
\text { classification } \\
\text { (Nyman, et al. } 1975) \\
\text { modified }\end{array}$} \\
\hline 0 & $138 \& 20.20 \%$ & $89 \& 13.03 \%$ & $227 \& 33.24 \%$ \\
\hline+ & $80 \& 11.71 \%$ & $26 \& 3.81 \%$ & $106 \& 15.52 \%$ \\
\hline I & $157 \& 22.99 \%$ & $61 \& 8.93 \%$ & $218 \& 31.92 \%$ \\
\hline $\mathrm{I}+$ & $27 \& 3.95 \%$ & $22 \& 3.22 \%$ & $49 \& 7.17 \%$ \\
\hline II & $29 \& 4.25 \%$ & $25 \& 3.66 \%$ & $54 \& 7.91 \%$ \\
\hline $\mathrm{II}+$ & $10 \& 1.46 \%$ & $8 \& 1.17 \%$ & $18 \& 2.64 \%$ \\
\hline III & $5 \& 0.73 \%$ & $6 \& 0.88 \%$ & $11 \& 1.61 \%$ \\
\hline Total & $446 \& 65.30 \%$ & $237 \& 34.70 \%$ & $683 \& 100 \%$ \\
\hline \multicolumn{4}{|l|}{$\begin{array}{c}\text { Original } \\
\text { classification } \\
(\text { Nyman, et al. } 1975)\end{array}$} \\
\hline 0 & $138 \& 20.20 \%$ & $89 \& 13.03 \%$ & $227 \& 33.24 \%$ \\
\hline $\mathrm{I}$ & $237 \& 34.70 \%$ & $87 \& 12.74 \%$ & $324 \& 47.44 \%$ \\
\hline II & $56 \& 8.20 \%$ & $47 \& 6.88 \%$ & $103 \& 15.08 \%$ \\
\hline III & $15 \& 2.20 \%$ & $14 \& 2.05 \%$ & $29 \& 4.25 \%$ \\
\hline Total & $446 \& 65.30 \%$ & $237 \& 34.70 \%$ & $683 \& 100 \%$ \\
\hline
\end{tabular}

Table 3. Main clinical and radiographic parameters

\begin{tabular}{|c|c|}
\hline $\begin{array}{c}\text { Main parameters } \\
\qquad(N=683)\end{array}$ & Mean \pm SD $(\mathrm{mm})$ \\
\hline \multicolumn{2}{|l|}{ Clinical parameters } \\
\hline CAL $_{\text {max }}$ & $6.87 \pm 1.91$ \\
\hline$P D_{\max }$ & $6.02 \pm 1.92$ \\
\hline \multicolumn{2}{|c|}{ Radiographic parameters } \\
\hline Mesial RBL & $5.49 \pm 2.24$ \\
\hline Distal RBL & $5.77 \pm 2.17$ \\
\hline $\begin{array}{c}\text { Mean RBL } \\
\text { (Mesial \& Distal) }\end{array}$ & $5.63 \pm 2.21$ \\
\hline Mesial RBS & $9.07 \pm 2.81$ \\
\hline Distal RBS & $8.74 \pm 2.76$ \\
\hline $\begin{array}{c}\text { Mean RBL } \\
\text { (Mesial \& Distal) }\end{array}$ & $8.91 \pm 2.79$ \\
\hline
\end{tabular}

Abbreviations: $\mathrm{CAL}$ : Maximum clinical attachment loss per tooth; PD : Maximum probing pocket depth per tooth; RBL: Linear radiographic bone loss per tooth; RBS: Linear radiographic bone support per tooth; SD: Standard deviation 
Table 4. Statistical comparison of mean clinical and radiographic parameters among various mobility groups

\begin{tabular}{|c|c|c|c|c|}
\hline \multirow[t]{2}{*}{ Mobility groups } & \multicolumn{2}{|c|}{ Clinical parameters } & \multicolumn{2}{|c|}{ Radiographic parameters } \\
\hline & $\begin{array}{c}\mathbf{C A L}_{\max } \\
\text { Mean }(\mathbf{m m})\end{array}$ & $\begin{array}{c}\mathbf{P D}_{\max } \\
\text { Mean (mm) }\end{array}$ & $\begin{array}{c}\text { RBL } \\
\text { Mean (mm) }\end{array}$ & $\begin{array}{c}\text { RBS } \\
\text { Mean }(\mathbf{m m})\end{array}$ \\
\hline Mobile teeth $(N=456)$ & 7.05 & 6.18 & 6.01 & 8.45 \\
\hline Non-mobile teeth $(N=227)$ & 6.52 & 5.68 & 4.86 & 9.81 \\
\hline$p$ value for Wilcoxon-Mann-Whitney test & $* * *$ & $* *$ & $* * *$ & $* * *$ \\
\hline $\begin{array}{l}\text { Seven }(\mathbf{0},+, \mathbf{I}, \mathbf{I}+, \mathbf{I I}, \mathbf{I I}+, \mathbf{I I I}) \text { or four }(\mathbf{0}, \mathbf{I}, \mathbf{I I}, \mathbf{I I I}) \text { mobility grade groups } \\
p \text { value for Kruskal-Wallis test }\end{array}$ & $* * *$ & $* * *$ & $* * *$ & $* * *$ \\
\hline
\end{tabular}

Abbreviations: $\mathrm{CAL}_{\max }$ : Maximum clinical attachment loss per tooth; $\mathrm{PD}_{\max }$ : Maximum probing pocket depth per tooth; RBL: Mean (based on mesial and distal measurements) linear radiographic bone loss per tooth; RBS: Mean (based on mesial and distal measurements) linear radiographic bone support per tooth; SD: Standard deviation

$* *$ Statistically significant difference $(p<0.01)$

$* * *$ Statistically significant difference $(p<0.001)$

( $p=0.05$ ), teeth with a periapical radiolucency with dimensions $\geq 1 \mathrm{~mm}$ $\times 1 \mathrm{~mm}(p=0.037)$ and smokers $(p=0.029)$.

With respect to the association of continuous variables $\left(\mathrm{CAL}_{\max }\right.$ per tooth, $\mathrm{PD}_{\max }$ per tooth, mean RBL per tooth and mean RBS per tooth) with the grade of tooth mobility, the Kruskal-Wallis test for nonparametric data revealed that $\mathrm{CAL}_{\max }$ per tooth, $\mathrm{PD}_{\max }$ per tooth and mean RBL per tooth were statistically significantly positively related to the grade of tooth mobility $(p<0.001$, Table 4$)$, whereas mean RBS per tooth was statistically significantly negatively associated with tooth mobility grade $(p<0.001$, Table 4$)$. In contrast, age, FMPS, GI-S and FMBS were not statistically significantly related to the grade of tooth mobility $(p>0.05)$.

The association of patient-related, clinical and radiographic parameters with the grade of tooth mobility was statistically reevaluated by using a four-grade ( 0, I, II, III) classification, in accordance with the original classification of tooth mobility proposed by Nyman, et al. (1975). For all statistical tests performed, the statistical significance found was not different from the statistical significance demonstrated by the use of the seven-grade $(0,+$, I, I+, II, II+, III) modification of the classification proposed by Nyman et al. (1975) (Table 4).

\section{Discussion}

The present cross-sectional study examined the association of various parameters (patient-related and tooth-related anatomical, clinical and radiographic parameters) with the presence and grade of mobility of periodontally involved teeth in chronic periodontitis patients, prior to the initiation of periodontal therapy.

Overall, in the present study clinical parameters $\left(\mathrm{CAL}_{\max }\right.$ per tooth and $\mathrm{PD}_{\max }$ per tooth) and the radiographic parameter (mean RBL per tooth) reflecting the severity of periodontal destruction were significantly positively associated both with the presence and grade of tooth mobility. These findings can be interpreted by the fact that increased periodontal destruction is equivalent to reduced root surface area with connective tissue attachment, therefore resulting in increased tooth mobility [17]. As anticipated, based on the same reasoning, the radiographic periodontal parameter (mean RBS per tooth) reflecting the amount of the remaining supporting periodontal tissues, in contrast, was significantly negatively associated with both the presence and grade of tooth mobility. Based on these findings, the significance of tooth mobility measurement in clinical practice is that it serves as a valuable clinical indicator of the status of the supporting periodontal tissues [2,17].

Similar findings have been previously reported in the literature. Self-reported presence of tooth mobility (as a dichotomous variable) was highly significantly associated with the presence of periodontitis and therefore could serve as a predictor of the presence of periodontitis with high specificity and low sensitivity [32-34]. The grade of tooth mobility was positively associated with the severity of chronic periodontitis [35]. Teeth with mobility exhibited significantly higher CAL and PD values and lower radiographic alveolar bone support, compared with teeth without mobility $[19,20]$. In a previous crosssectional study [19] conducted prior to periodontal therapy, the degree of mobility of maxillary anterior teeth (as measured by using Mühlemann's periodontometer) [36] was primarily correlated with $\mathrm{CAL}$ and, to a lower degree, with radiographic alveolar bone support. In another cross-sectional study [22], the degree of tooth mobility substantially correlated with the amount of radiographic alveolar bone loss and CAL. Similarly, the degree of tooth mobility was primarily correlated with radiographic alveolar bone loss and, less strongly, with PD [21]. A cross-sectional study [37] of elderly patients (mean age 69.3 years; age range 65 to 75 years) revealed that the grade of tooth mobility was statistically significantly positively correlated with radiographic alveolar bone loss. In a retrospective study $[38,38]$, the presence of initial (i.e. prior to the initiation of active periodontal therapy) tooth mobility, as a dichotomous variable, was significantly associated with baseline PD.

In the present study, smokers (consumers of $\geq 10$ cigarettes / day) exhibited a significantly higher tooth mobility grade than non-smokers ( $<10$ cigarettes / day). To date, systematic or comprehensive reviews have provided sufficient evidence demonstrating that smoking is associated with the prevalence and severity of periodontal diseases, is a risk factor for the initiation and progression of periodontal diseases [40] and a prognostic / predictive factor for disease progression [41], and finally is associated with a less favourable response to periodontal therapy $[39,42]$. Furthermore, the potential biological mechanisms accounting for these effects of smoking have been extensively reviewed $[39,43]$. Smokers presented statistically significantly higher tooth mobility grade than non-smokers or never-smokers [22,44-46], which could be attributed to the fact that smokers present a higher severity of periodontal disease (e.g. in terms of CAL and PD) [44-46], than nonsmokers or never-smokers [39,44-46]. After adjustment for both age and calculus, cigarette smokers (but not pipe / cigar smokers) exhibited lower tooth mobility scores than non-smokers [47]. A case-control study [48] demonstrated a tendency for a slightly higher percentage of mobile teeth per patient in smokers, compared with either former smokers or non-smokers; however, this tendency did not reach statistical significance.

In the present study, single-rooted teeth and teeth exhibiting periapical radiolucency with dimensions $\geq 1 \mathrm{~mm} \times 1 \mathrm{~mm}$ presented a statistically significantly higher grade of tooth mobility, compared with multi-rooted teeth and teeth without periapical radiolucency, 
respectively. An older study [4] reported that the incisors present the highest mobility measurements, whereas the molars exhibit the lowest mobility measurements. The statistically significantly lower mobility in multi-rooted teeth may be explained primarily by the lower root surface area with connective tissue attachment [17] and the presence of more than one root perse.

In the present study, patient age, clinical indices (FMPS, GI-S and FMBS) reflecting the level of control of dental plaque and gingival / periodontal inflammation, respectively, and the type of radiographic alveolar bone loss (horizontal or angular) were not statistically significantly associated with both the presence and grade of tooth mobility.

An older study [4] reported that children presented higher tooth mobility values in comparison with adults, but the present study included only adults and therefore these findings cannot be compared. A previous cross-sectional study [49] in a Kenyan population showed no clear association between the proportion of mobile teeth and age. As reviewed in detail in the literature [40], a bulk of cross-sectional studies revealed a significant association between age and the prevalence, severity and extent of periodontitis, as well as the resultant tooth mobility and/or tooth loss. For example, age was statistically significantly positively associated with tooth mobility grade $[44,50]$. However, cross-sectional studies are able to reveal a statistical relation, but are not sufficient to prove a cause-and-effect relation (i.e. the presence of a causal factor) [51,52]. Reviews [40,41] have included longitudinal studies, reporting conflicting findings for the effect of ageing on the progression of periodontitis (significant positive effect or no effect).

The relation between age and the prevalence, severity and extent of periodontitis could probably be the result of the accumulation of periodontal destruction over the course of time, rather than the effect of the increasing age per se $[40,41]$. In line with this concept, a systematic review [53] concluded that age should not be regarded as a risk factor for the survival of tooth-supported fixed prosthetic restorations. Despite the fact that the increasing age appears to be neither an aetiological factor [52], nor a risk factor [51,52,54] for periodontitis, the ratio of the amount of periodontal destruction/age seems to be a valid predictor of future progression of periodontitis [40,41]. This suggests that between two patients with the same level of attachment loss, the younger individual could be regarded as being more susceptible to periodontitis and presenting a higher risk for future disease progression, compared with the older subject $[39,40,41]$.

In the present study, gender was not significantly associated with the grade of tooth mobility but was significantly related to the presence of tooth mobility, since females exhibited tooth mobility slightly more often than males; however, it should be pointed out that the latter difference marginally reached statistical significance. Higher tooth mobility values in females than in males was previously reported [4]. In contrast, no statistically significant difference in tooth mobility grade between males and females was demonstrated [22,44], even though statistically significantly higher CAL and PD were present in males than in females [44]. Males were reported to present a higher severity of periodontal disease, in terms of CAL and PD, probably due to a lower level of oral hygiene measures [49,50]. Overall, it appears that more research is required for the complete clarification of the role of gender as a risk factor for periodontal diseases.

With respect to the association of the degree of tooth mobility with clinical indices reflecting the level of oral hygiene and/or the severity of gingival / periodontal inflammation, previous studies [19,21,22] revealed no significant correlation, regardless of the fact that the level of oral hygiene is associated with the prevalence and the severity of periodontitis, as well as future disease progression during maintenance $[40,44]$ and also irrespective of the finding that the presence of a bleeding on probing score $>25 \%$ in a given individual was associated with a higher risk for the progression of periodontitis [55]. In line with these findings, older studies reported physiological tooth mobility scores in gingivitis patients $[56,57]$.

In the present study, both the presence and grade of tooth mobility were not significantly associated with the type of radiographic alveolar bone loss (horizontal or angular). While this issue seems not to be essentially documented in the literature, few studies have examined the relation of this parameter to future progression of periodontitis. A retrospective study [58] revealed that the presence of angular radiographic alveolar bone loss at baseline was not associated with future progression of periodontitis (additional loss of supporting alveolar bone) during a 5 to 16 -year maintenance period, but another retrospective study [59] concluded that in patients not subjected to systematic periodontal therapy, angular osseous defects appear to be indicators for progressing periodontitis (further alveolar bone loss) over a 10 -year maintenance period. Therefore, it is clear that more studies are required on the role/effect of the type of radiographic bone loss.

Certain limitations exist in the present study. By definition, a crosssectional study examines the relationship between diseases (or other health-related characteristics) and other variables of interest, as they exist in a defined population at a particular time-point [60], but not over the course of time. Therefore, as already mentioned, this design by its nature can provide valuable information on statistical associations and thus indicate the presence of a potential/putative risk factor/risk indicator [51,52], but is not sufficient to document cause-and-effect relations and consequently the presence of an aetiological /causal factor [52] primarily because it cannot establish that the exposure to the suspected aetiological factor preceded the onset of the effect [51,52]. For example, tooth mobility could be the effect, but also the cause of CAL or radiographic alveolar bone loss. For the same reason, cross-sectional data by their nature are not appropriate to provide evidence for the presence of a prognostic factor / disease predictor [52] and therefore do not allow the prediction of future tooth mobility. In contrast, a longitudinal design, which accumulates information over the course of time, is essential to demonstrate the presence of an aetiological factor, a risk factor or a prognostic factor $[51,52,54]$ for tooth mobility. Longitudinal studies are also appropriate to examine whether tooth mobility itself could be an aetiological factor, or a prognostic factor for future periodontal status/conditions and progression of periodontal disease at individual sites in chronic periodontitis patients, both untreated and following periodontal therapy. It has been emphasized in the literature that the relation between tooth mobility and prognosis nowadays still remains unclear [61].

In the present study, the grade of tooth mobility was determined by the method of moving each tooth between the handles of two metallic dental instruments, which is clearly more subjective than standardized methods, such as the use of a measuring electronic device [21], particularly in cases when subtle differences of half a grade $(0.5$ $\mathrm{mm}$ ) need to be distinguished. In order to overcome this limitation, all measurements of tooth mobility grade were performed three times for each tooth by the same examiner. Another methodological limitation is that conventional radiographic methods provide solely 
two-dimensional information and, furthermore, image relatively accurately only the proximal alveolar bone loss or support [26]. Ideally, information on the amount of missing or existing alveolar bone should be three-dimensional, in order to accurately correlate with the grade of tooth mobility. On the other hand, the clinical and radiographic methods used in the present study have prevailed in everyday clinical practice and therefore have the advantage of reproducing and corresponding to the conditions usually met clinically. Primarily for this reason, conventional methods of tooth mobility assessment are still used in the literature in a plethora of studies [35,37,38,44-46].

Finally, an interesting observation is that more than $80 \%$ of teeth in the patient population examined in this study exhibited mobility grade 0 to I, whereas less than $20 \%$ presented mobility grade II to III (Table 2). Therefore, despite the fact that the majority of participants in this study exhibited severe, rather than mild or moderate periodontitis, study findings concern a tooth population essentially with zero-to-low average tooth mobility and should not be extrapolated to other tooth populations, that present moderate or high tooth mobility grade.

\section{Conclusions}

Within the limitations of the present study, the following conclusions may be drawn with respect to the association of various parameters with the presence or grade of mobility of periodontally involved teeth in chronic periodontitis patients prior to the initiation of periodontal therapy:

Maximum clinical attachment loss, maximum probing pocket depth and mean linear radiographic alveolar bone loss per tooth were significantly positively associated both with the presence and grade of tooth mobility.

The presence of smoking $\geq 10$ cigarettes/day and periapical radiolucency with dimensions $\geq 1 \mathrm{~mm} \times 1 \mathrm{~mm}$ were significantly positively associated with the grade of tooth mobility, while singlerooted teeth exhibit significantly higher tooth mobility grade, compared with multi-rooted teeth.

Mean linear radiographic alveolar bone support per tooth was significantly negatively associated with both the presence and grade of tooth mobility.

In contrast, patient age, type of radiographic alveolar bone loss (horizontal or angular) and clinical indices reflecting the level of oral hygiene and the severity of gingival/periodontal inflammation (full-mouth plaque or bleeding on probing score and gingival index simplified) are not significantly associated with both the presence and grade of tooth mobility.

The association of patient gender with the presence or grade of tooth mobility was not very clear and requires further investigation in the future.

\section{Statement of any potential Source of Funding and Conflicts of Interest}

The authors declare that they have no conflicts of interest and that no funding was used for this study.

\section{References}

1. Mühlemann HR (1954) Tooth mobility. The measuring method. Initial and secondary tooth mobility. J Periodontol 25: 22-29.

2. Giargia M, Lindhe J (1997) Tooth mobility and periodontal disease. J Clin Periodontol 24: 785-795. [Crossref]
3. Gher ME (1996) Non-surgical pocket therapy: dental occlusion. Ann Periodontol 1: 567-580. [Crossref]

4. Mühlemann HR (1960) Ten years of tooth mobility measurements. J Periodontol 31: $110-122$

5. Persson R, Svensson A (1980) Assessment of tooth mobility using small loads. I Technical device and calculations of tooth mobility in periodontal health and disease. $J$ Clin Periodontol 7: 259-275.

6. Ericsson I, Lindhe J (1984) Lack of significance of increased tooth mobility in experimental periodontitis. J Periodontol 55: 447-452. [Crossref]

7. Macapanpan LC, Weinmann JP (1954) The influence of injury to the periodontal membrane on the spread of gingival inflammation. J Dent Res 33: 263-272. [Crossref]

8. Glickman I (1963) Inflammation and trauma from occlusion, co-destructive factors in chronic periodontal disease. J Periodontol 34: 5-10.

9. Glickman I, Smulow JB (1962) Alterations in the pathway of gingival inflammation into the underlying tissues induced by excessive occlusal forces. J Periodontol 33: 7-13.

10. Glickman I, Smulow JB (1965) Effect of excessive occlusal forces upon the pathway of gingival inflammation in humans. J Periodontol 36: 141-147. [Crossref]

11. Glickman I, Smulow JB (1967) Further observations on the effects of trauma from occlusion in humans. J Periodontol 38: 280-293. [Crossref]

12. Glickman I, Smulow JB (1968) Adaptive alterations in the periodontium of the rhesus monkey in chronic trauma from occlusion. J Periodontol 39: 101-105. [Crossref]

13. Glickman I, Smulow JB (1969) The combined effects of inflammation and trauma from occlusion in periodontitis. Int Dent $J$ 19: 393-407. [Crossref]

14. Svanberg G, Lindhe J (1973) Experimental tooth hypermobility in the dog. A methodological study. Odontol Revy 24: 269-282. [Crossref]

15. Svanberg G (1974) Influence of Crossref trauma from occlusion on the periodontium of dogs with normal or inflamed gingivae. Odontol Revy 25: 165-178. [Crossref]

16. Ericsson I, Lindhe J (1977) Lack of effect of trauma from occlusion on the recurrence of experimental periodontitis. J Clin Periodontol 4: 115-127. [Crossref]

17. Muehlemann HR, Savdir S, Rateitschak KH (1965) Tooth mobility--its causes and significance. J Periodontol 36: 148-153. [Crossref]

18. Pihlstrom BL, Anderson KA, Aeppli D, Schaffer EM (1986) Association between signs of trauma from occlusion and periodontitis. J Periodontol 57: 1-6. [Crossref]

19. Khoo KK, Watts TL (1988) Upper anterior tooth mobility. Selected associations in untreated periodontitis. J Periodontol 59: 231-237.

20. Jin LJ, Cao CF (1992) Clinical diagnosis of trauma from occlusion and its relation with severity of periodontitis. J Clin Periodontol 19: 92-97. [Crossref]

21. Schulte W, d'Hoedt B, Lukas D, Maunz M, Steppeler M (1992) Periotest for measuring periodontal characteristics-Correlation with periodontal bone loss. $J$ Periodontal Res 27: 184-190.

22. Demirel K, Gür H, Meriç H, Sevük C (1997) Damping characteristics of teeth with periodontal breakdown: correlation of mobility meter values with bone and attachment loss. J Periodontol 68: 166-171. [Crossref]

23. O'Leary TJ, Drake RB, Naylor JE (1972) The plaque control record. J Periodontol 43 : 38. [Crossref]

24. Lindhe J (1981) Textbook of Clinical Periodontology, 1st ed. Copenhagen: Munksgaard: 327-352.

25. Ainamo J, Bay I (1975) Problems and proposals for recording gingivitis and plaque. Int Dent J 25: 229-235. [Crossref]

26. Pepelassi EA, Tsiklakis K, Diamanti-Kipioti A (2000) Radiographic detection and assessment of the periodontal endosseous defects. $J$ Clin Periodontol 27: 224-230. [Crossref]

27. Armitage G (1999) Development of a classification system for periodontal diseases and conditions. Ann Periodontol 4: 1-6.

28. Schwarz F, Sculean A, Berakdar M, Georg T, Reich E, et al. (2003) Clinical evaluation of an Er:YAG laser combined with scaling and root planing for nonsurgical periodontal treatment. A controlled, prospective clinical study. J Clin Periodontol 30: 26-34.

29. Döri F, Huszár T, Nikolidakis D, Arweiler NB, Gera I, et al. (2007) Effect of plateletrich plasma on the healing of intrabony defects treated with an anorganic bovine bone mineral and expanded polytetrafluoroethylene membranes. J Periodontol 78: 983-990. [Crossref] 
30. Nyman S, Lindhe J, Lundgren D (1975) The role of occlusion for the stability of fixed bridges in patients with reduced periodontal tissue support. $J$ Clin Periodontol 2: 5366. [Crossref]

31. Pepelassi EA, Diamanti-Kipioti A (1997) Selection of the most accurate method of conventional radiography for the assessment of periodontal osseous destruction. $J$ Clin Periodontol 24: 557-567.

32. Dietrich T, Stosch U, Dietrich D, Schamberger D, Bernimoulin JP, et al. (2005) The accuracy of individual self-reported items to determine periodontal disease history. Eur J Oral Sci 113: 135-140. [Crossref]

33. Dietrich T, Stosch U, Dietrich D, Kaiser W, Bernimoulin JP, et al. (2007) Prediction of periodontal disease from multiple self-reported items in a German practice-based sample. J Periodontol 78: 1421-1428.

34. Dietrich T, Kaiser W, Naumann M, Stosch U, Schwahn C, et al. (2009) Validation of a multivariate prediction rule for history of periodontitis in a separate population. $J$ Clin Periodontol 36: 493-497. [Crossref]

35. Agrawal AA, Kapley A, Yeltiwar RK, Purohit HJ (2006) Assessment of single nucleotide polymorphism at IL-1A+4845 and IL-1B+3954 as genetic susceptibility test for chronic periodontitis in Maharashtrian ethnicity. J Periodontol 77: 1515-1521.

36. Muhlemann HR (1951) Periodontometry, a method for measuring tooth mobility. Oral Surg Oral Med Oral Pathol 4: 1220-1233. [Crossref]

37. Wheeler TT, McArthur WP, Magnusson I, Marks RG, Smith J, et al. (1994) Modeling the relationship between clinical, microbiologic, and immunologic parameters and alveolar bone levels in an elderly population. J Periodontol 65: 68-78. [Crossref]

38. König J, Plagmann HC, Rühling A, Kocher T (2002) Tooth loss and pocket probing depths in compliant periodontally treated patients: a retrospective analysis. $J$ Clin Periodontol 29: 1092-1100. [Crossref]

39. Johnson GK (1999) Tobacco use and the periodontal patient. J Periodontol 1999;70:1419-1427.

40. Ainamo J, Ainamo A (1996) Risk assessment of recurrence of disease during supportive periodontal care. Epidemiological considerations. J Clin Periodontol 23: 232-239. [Crossref]

41. Heitz-Mayfield LJ (2005) Disease progression: identification of high-risk groups and individuals for periodontitis. J Clin Periodontol 32 Suppl 6: 196-209. [Crossref]

42. Heasman L, Stacey F, Preshaw PM, McCracken GI, Hepburn S, Heasman PA (2006) The effect of smoking on periodontal treatment response: a review of clinical evidence. J Clin Periodontol 33: 241-253.

43. Palmer RM, Wilson RF, Hasan AS, Scott DA (2005) Mechanisms of action of environmental factors--tobacco smoking. J Clin Periodontol 32 Suppl 6: 180-195. [Crossref]

44. Martinez-Canut P, Lorca A, Magán R (1995) Smoking and periodontal disease severity. $J$ Clin Periodontol 22: 743-749. [Crossref]
45. Kerdvongbundit V, Wikesjö UM (2000) Effect of smoking on periodontal health in molar teeth. J Periodontol 71: 433-437. [Crossref]

46. Kerdvongbundit V, Wikesjö UME (2002) Prevalence and severity of periodontal disease at mandibular molar teeth in smokers with regular oral hygiene habits. $J$ Periodontol 73: 735-740.

47. Feldman RS, Bravacos JS, Rose CL (1983) Association between smoking differen tobacco products and periodontal disease indexes. J Periodontol 54: 481-487.

48. Calsina G, Ramón JM, Echeverría JJ (2002) Effects of smoking on periodontal tissues. $J$ Clin Periodontol 29: 771-776. [Crossref]

49. Baelum V, Fejerskov O, Manji F (1988) Periodontal diseases in adult Kenyans. J Clin Periodontol 15: 445-452. [Crossref]

50. Wang QT, Wu ZF, Wu YF, Shu R, Pan YP, et al. (2007) Epidemiology and preventive direction of periodontology in China. J Clin Periodontol 34: 946-951. [Crossref]

51. Burt BA (2001) Definitions of risk. J Dent Educ 65: 1007-1008. [Crossref]

52. Papapanou PN, Lindhe J (2003) Epidemiology of periodontal diseases. In: Lindhe J, Karring T, Lang NP, eds. Clinical Periodontology and Implant Dentistry, 4th ed. Copenhagen: Blackwell Munksgaard, Blackwell Publishing Ltd; 61-62.

53. Ioannidis G, Paschalidis T, Petridis HP, Anastassiadou V (2010) The influence of age on tooth supported fixed prosthetic restoration longevity. A systematic review. J Dent 38: $173-181$.

54. Beck JD (1998) Risk revisited. Community Dent Oral Epidemiol 26: 220-225. [Crossref]

55. Joss A, Adler R, Lang NP (1994) Bleeding on probing. A parameter for monitoring periodontal conditions in clinical practice. J Clin Periodontol 21: 402-408.

56. Hotz P, Son S, Mühlemann HR (1971) The effect of marginal gingivitis on tooth mobility. Helv Odontol Acta 15: 103-106. [Crossref]

57. Donzé Y, Krüger J, Ketterl W, Rateitschak KH (1973) Treatment of gingivitis with Cavitron or hand instruments: a comparative study. Helv Odontol Acta 17: 31-37. [Crossref]

58. Pontoriero R, Nyman S, Lindhe J (1988) The angular bony defect in the maintenance of the periodontal patient. J Clin Periodontol 15: 200-204. [Crossref]

59. Papapanou PN, Wennström JL (1991) The angular bony defect as indicator of further alveolar bone loss. J Clin Periodontol 18: 317-322. [Crossref]

60. Centre for Reviews and Dissemination, University of York. Systematic reviews. CRD's guidance for undertaking reviews in health care. Layerthorpe, York: York Publishing Services Ltd; 2009:264.

61. Kwok V, Caton JG (2007) Prognosis revisited: a system for assigning periodontal prognosis. J Periodontol 78: 2063-2071.

Copyright: (C2019 Giannakoura A. This is an open-access article distributed under the terms of the Creative Commons Attribution License, which permits unrestricted use, distribution, and reproduction in any medium, provided the original author and source are credited. 